\title{
The role of living context in prescription opioid injection and the associated risk of hepatitis $\mathrm{C}$ infection
}

Sacks-Davis $\mathrm{R}^{1,2}$, Daniel $\mathrm{M}^{3,4,5}$, Roy $\mathrm{E}^{6,7}$, Kestens $\mathrm{Y}^{8}$, Zang $\mathrm{G}^{8}$, Ramos $\mathrm{Y}^{8}$, Hellard $\mathrm{M}^{2,9}$, Jutras Aswad D ${ }^{8,10}$, Bruneau J ${ }^{8,11}$

1.-Department of Medicine, University of Melbourne, Melbourne, Australia

2. Burnet Institute, Melbourne, Australia

3. School of Population Health, University of South Australia, Adelaide, Australia

4. Department of Medicine, St. Vincent's Hospital, The University of Melbourne, Melbourne, Australia

5. South Australian Health and Medical Research Institute, Adelaide, Australia

6. Department of Community Health Sciences, Faculty of Medicine and Health Sciences, Université de Sherbrooke, Longueuil, Canada

7. Institut National de Santé Publique, Montréal, Canada

8. Research Center, Centre Hospitalier de l'Université de Montréal (CRCHUM), Montréal, Canada

9. Department of Epidemiology and Preventive Medicine, Monash University, Melbourne, Australia

10. Department of Psychiatry, Université de Montréal, Montréal, Canada

11. Department of Family and Emergency Medicine, Université de Montréal, Montréal, Canada

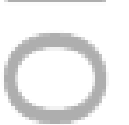

Corresponding author:

Julie Bruneau

Julie.bruneau@uMontréal.ca

900 rue Saint-Denis, Montréal, Qc, Canada

Phone +15148908000 ext 35713, Fax +1 $514412-7280$

Running head: Living context, POI, and HCV infection

Word count: 3500

This is the author manuscript accepted for publication and has undergone full peer review but has not been through the copyediting, typesetting, pagination and proofreading process, which may lead to differences between this version and the Version of Record. Please cite this article as doi: $10.1111 /$ add. 13470

This article is protected by copyright. All rights reserved. 
Declarations of competing interest: $\mathrm{MH}$ receives funding from Gilead Sciences and Abbvie for investigator-initiated independent research studies.

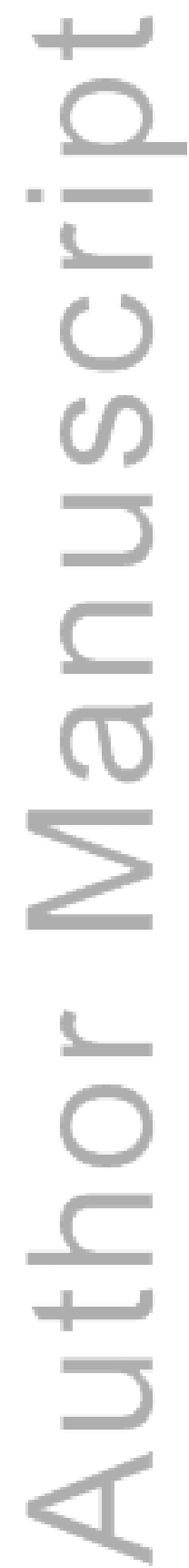

This article is protected by copyright. All rights reserved. 


\section{Abstract}

Background and aims: Prescription opioid injection (POI) is a leading risk factor for hepatitis $\mathrm{C}$ virus (HCV). Residential context relates to high-risk injection behavior. This study assessed whether residence in the inner city (vs. surrounding areas in Montréal Island) modified the effects of correlates of POI or the relationship between POI and HCV incidence.

Design: Prospective cohort study.

Setting: Montréal, Canada

Participants: 854 people who inject drugs (18\% female, 25\% age<30) living on Montréal Island, were interviewed every 3-6 months from 2004-2012.

Measurements: Study visits included HCV antibody testing and an interviewer-administered questionnaire. Generalized estimating equations were used to test whether place of residence modified the effects of correlates of POI. Cox regression was used test whether place of residence modified the relationship between POI and HCV incidence.

Findings: At baseline, inner-city participants were more likely to report POI in the past month $(40 \%$ vs $25 \%, \mathrm{p}<0.001)$. The association between POI and heroin injection, syringe sharing and sharing of injecting equipment varied according to place of residence and was greater in the inner city. The hazard of HCV infection associated with POI was greater among inner-city participants compared to those in the surrounding areas (adjusted HR: 3.19, 95\%CI: $1.85-5.51$ vs HR: $1.26,95 \% \mathrm{CI}: 0.65-2.42, \mathrm{p}=0.025)$.

Conclusions: Among people who inject prescription opioids in Montréal, Canada, those who live in inner-city areas are more likely to engage in injecting-related risk behaviors and have a higher risk of hepatitis $\mathrm{C}$ virus infection than those who live in the suburbs.

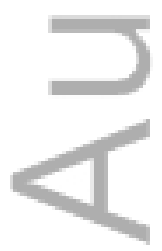

This article is protected by copyright. All rights reserved. 


\section{Introduction}

Living context is associated with injecting-related risk behaviors and harms. High-risk, innerurban "drug scene" neighborhoods have been described for cities including Montréal $(1,2)$, Vancouver (3-7), Winnipeg $(8,9)$ and Baltimore (10). Such areas are characterized by socioeconomic disadvantage, violence, recognized illicit drug markets and high levels of drug use $(2-4,11)$. For people who inject drugs (PWID), residing in such neighborhoods with immediate access to large injecting networks $(9,12)$ is associated with injecting-related risk behaviors $(2,6,7,10)$. These contexts contribute to high concentration of risk of blood-borne infection (5) and are targets for harm reduction services (1).

Non-medical use of prescription opioids has increased markedly in high-income countries over the last 20 years, particularly in North America (13-16). In Canada, a multisite study conducted in 2001-2005 found that prescription opioids had surpassed heroin as the primary drug used by regular opiate users in five of seven cities (17).

Among PWID, prescription opioid injection (POI) is associated with harms including hepatitis $\mathrm{C}$ virus ( $\mathrm{HCV}$ ) infection. Cross-sectional studies in urban and rural settings in the US indicate that POI is a stronger risk factor for $\mathrm{HCV}$ infection than is the injection of other drugs (18-20). Even more compellingly, we previously demonstrated that POI was a leading predictor of incident HCV infection in a prospective cohort of PWID in Montréal (21).

Earlier reports by this team have documented an elevated prevalence of correlates of HCVrelated risk behaviors such as frequency of injecting and socioeconomic disadvantage in Montréal's inner city area. The impact of such factors on high-risk injection behavior, however, appeared to be mitigated by a greater availability of harm reduction services in the inner city (1). These services may not be adequate in relation to the rising prevalence of POI: a recent ethnographic study of POI in inner-city Montréal identified novel HCV-related risk behaviors not accounted for by current harm reduction strategies (22).

While much evidence exists that residential context is associated with a range of injectingrelated risk behaviors and harms, the relationship between residential context, POI and risk of HCV infection has not been assessed. This study assessed among PWID participating in a 
cohort study interactions between place of residence (inner city vs. the surrounding areas on the Island of Montréal) and correlates of POI. For PWID who were HCV-negative at baseline, we also assessed whether HCV incidence was more strongly associated with POI for those residing in the inner city vs. the surrounding areas.

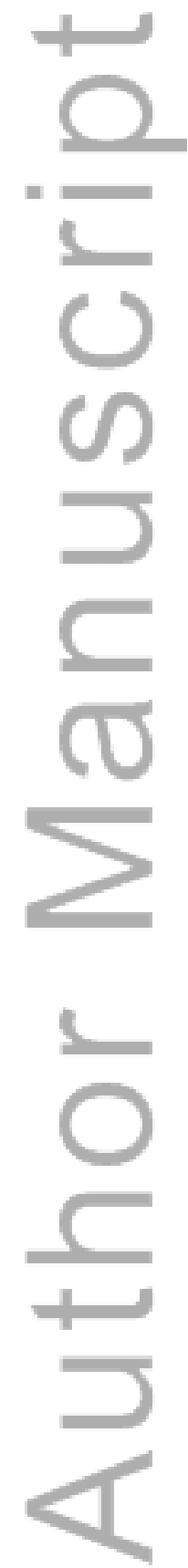

This article is protected by copyright. All rights reserved. 


\section{Methods}

\section{Setting}

This study was conducted on the Island of Montréal, having a population of 1.9 million people and a land base of $500 \mathrm{~km}^{2}$ divided into 19 boroughs and 15 semi-independent municipalities (23). Consistent with previous research (2), Ville-Marie borough was chosen to represent inner-city Montréal (Figure 1). Ville-Marie is the central and oldest portion of the city, and has the highest levels of socioeconomic disadvantage and crime of all boroughs and municipalities (Table 1) $(2,24-26)$. Ville-Marie is also the only borough to prioritise partnerships and interventions to enhance cohabitation with PWID in its strategic plan (27).

\section{Participants}

Participants were selected from the HEPatitis COhort (HEPCO), an ongoing open prospective cohort of PWID in Montréal. HEPCO was established in 2004 to investigate determinants of $\mathrm{HCV}$ infection. To be eligible for the study, participants had to have injected drugs within the six months prior to enrolment, be at least 18 years of age and reside on the Island of Montréal. Participants were recruited via street-level strategies such as word-of-mouth referral, community-based organizations, and from a previous prospective study of HIV transmission whose participants had been recruited using similar strategies. From 2004 to mid-March 2011, participants were followed up at six-month intervals and from mid-March 2011 onward, at three-month intervals. Recruitment and follow-up have been described previously (21).

For the purpose of this analysis, interviews in which participants did not provide a valid postal code, or provided a postal code associated with residence outside the Island of Montréal or in a correctional facility, were excluded because place of residence could not be categorized for the study setting. Data extractions cover the period 2004-2012. Participants with at least two eligible interviews were included in the analysis. Participants who were HCV seronegative at study enrolment and had at least one additional HCV test were included in HCV incidence analysis. A flowchart detailing participant recruitment, follow-up and inclusion in analyses is provided in Figure 2.

\section{Measures}


Place of residence was coded as either the inner city or the surrounding areas on the Island of Montréal. Residential location was determined by asking participants for the postal code corresponding to their dwelling place, defined as the place where they had most often slept during the past month. For participants with no fixed address, the postal code of the closest street intersection to where they reported having slept most often was used. Postal codes were geocoded using GeoPinPoint Suite software (DMTI Spatial, Inc. Markham, Ontario).

POI was defined on the basis of detailed questions about drug and other psychoactive substance use in the past month. Participants were asked whether they had injected opiates other than heroin, buprenorphine-naloxone and methadone for non-medical purposes in the past month. An exhaustive list of commercial and street denominations was proposed to help participants identify prescription opioids among substances in circulation, including opioids such as hydrocodone (dilaudid, dilos) and oxycodone (percs, oxycontin, oxys).

$\mathrm{HCV}$ infection was detected by the presence of $\mathrm{HCV}$ antibodies following a prior negative $\mathrm{HCV}$ antibody test. The date of HCV seroconversion was considered to be the midpoint between the dates of the participants' last negative and the first positive HCV test. A positive $\mathrm{HCV}$ antibody test was determined by enzyme immunoassay assay (Abbott Laboratories). Specimens with indeterminate results were sent for confirmatory tests by dual EIA and/or RIBA (gold standard).

Individual covariates included age (greater than or less than 30), gender, housing situation, unstable income, incarceration, cocaine and heroin injection, crack cocaine use, frequency of injection drug use, syringe sharing, sharing of auxiliary injecting equipment and public injection.

A measure of local socioeconomic disadvantage (surrounding the place of residence) was included as a covariate in order to adjust for local socioeconomic variations within the inner city as well as surrounding areas. Including such a covariate enables fairer comparisons to be made on the basis of geographic region (inner city vs. surrounding areas) where such contrasts are not confounded by local level of socioeconomic disadvantage. Local socioeconomic disadvantage was defined as the percentage of households below Statistics 
Canada's before tax low-income cut-off (LICO) within 250 meters of participants' places of residence. The LICO are income thresholds that identify households that would be expected to spend 20 percentage points more than the average household of the same size on shelter, food and clothing. The data on percentage of households below the LICO were derived for enumeration areas (600 persons on average) using data from the 2006 Canadian Census. Local residential neighbourhoods were represented as Manhattan distance buffers - that is, irregularly shaped buffer zones, where all extremities of the zone are within $250 \mathrm{~m}$ walking distance from the residential postal code by road. Postal codes typically represent one face of a city block. In 2001, there were 13308 city blocks in the Island of Montréal, and 43125 postal codes (3.24 postal codes per city block) (26). Population-weighted averages were used to compute the percentage of households below the LICO for each participant's buffer zone. Local socioeconomic disadvantage was dichotomised at the median value at study baseline, and was classified as high ( $\geq 40 \%$ of households below the LICO) or low.

Unstable housing was defined as living on the street, in shelters or in apartment-hotels rented on a monthly basis, based on the main situation in the past three months (21). Short-term incarceration was defined as any episode in the past three months. Cocaine and heroin injection, crack cocaine use and frequency of injecting drug use were all measured as use in the past month (yes/no). Unstable income, syringe sharing, sharing of auxiliary injecting equipment and public injection were measured for the prior six months to interviews conducted from 2004-March 2011, and for the prior three months for interviews conducted from April 2011-2012. Unstable income was defined on the basis of reporting any income from the following sources: support from friends and family, sex work and related employment (e.g., pimping), illegal activities (e.g., robbery, fraud, or drug trade), selling personal items, and begging, among other activities.

Place of residence, POI, and all covariates other than age, gender, and education were modelled as time-varying.

Statistical analysis 
Socio-demographic characteristics of the sample at baseline were summarized using frequency and percentages. Chi-squared tests were used to assess differences in baseline characteristics between participants residing in the inner city vs. surrounding areas.

Generalized estimating equation (GEE) models were conducted to identify the correlates of POI (28), using a binomial family function, a logit link and an exchangeable withinparticipant correlation structure. Univariable models were used to identify correlates of POI in the entire cohort. Interactions between each of the potential correlates of POI and place of residence (inner-city vs. surrounding areas) were tested. For each model, odds ratios (OR) of POI, corresponding 95\% confidence intervals (CI), and p-values for interaction were estimated.

HCV infection rates were estimated using Kaplan-Meier survival analysis (29). Cox proportional hazards regression was used to estimate crude and adjusted hazard ratios (HR) and corresponding 95\% CI, and to evaluate effect modification by place of residence (innercity vs. surrounding areas) on the relationship between POI and HCV incidence. The final multivariable model was adjusted for covariates selected using the purposeful selection procedure (30). This procedure involves identifying statistically significant variables as well as those that changed a significant variable's beta coefficient by more than $20 \%$ to retain in the final multivariable model. Two multivariable models are presented in the paper: one contains only the variables identified using the purposeful selection criteria, and the other additionally includes age, gender and syringe sharing as important a priori covariates of the risk of HCV transmission (31-35) as well as local-area socioeconomic disadvantage. The assumption of proportional hazards was assessed using scaled Schoenfeld residuals.

Given that the frequency of follow-up was increased Mid-March 2011, sensitivity analyses were conducted excluding data from Mid-March 2011 onward in order to assess the impact of this change in study protocol.

For all hypothesis testing, $\mathrm{p}$-value $<0.05$ was used as the criterion for statistical significance. All analyses were conducted using Stata 13 (College Station, Texas 2015).

\section{Ethics}


All participants provided informed consent. Ethical approval was provided by the institutional review board of the Centre Hospitalier de l'Université de Montréal.

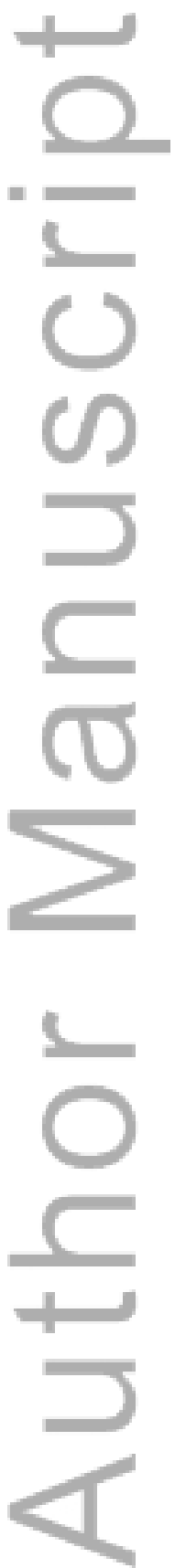

This article is protected by copyright. All rights reserved. 


\section{Results}

\section{Participant characteristics}

Of 1198 participants recruited, 944 (79\%) were interviewed at least twice. Of these, eight did not provide a valid postcode, 14 were incarcerated at follow-up and 68 had moved away from Montréal Island. The remaining 854 participants were eligible for inclusion (Figure 2). At study entry, approximately half of these resided in the inner city and half resided in the surrounding areas on Montréal Island. Between the first two interviews, 62\% ( $n=530)$ moved residences. Of these, $62 \%(n=327)$ moved within the inner city or surrounding areas, and $38 \%(n=203)$ moved between the inner city and surrounding areas. One quarter of participants were younger than 30 years and $18 \%$ were female. Approximately one third had injected prescription opioids in the month prior to study entry. Participant characteristics are described in detail in Table 2.

Participants residing in the inner city were different to those residing in surrounding areas. They were less likely to be female, more likely to report previous incarceration, recent unstable income, unstable housing, living in neighborhoods with high local socioeconomic disadvantage, having recently injected prescription opioids and cocaine, and used crack, and less likely to have recently injected heroin. Participants in the inner city were also more likely to have engaged in recent public injecting (Table 2).

\section{Correlates of POI}

Correlates of POI are presented in Table 3. At baseline, POI was associated with young age, unstable income and housing, heroin injection, crack use, daily or more frequent injection, public injecting, syringe and auxiliary equipment sharing, living in neighborhoods with high local socioeconomic disadvantage and living in the inner city. These factors and not being college educated were associated with POI use throughout the study period. Overall, PWID residing in the inner city were 1.5 times more likely to inject prescription opioids (Table 3 ).

Generally, correlates of POI were similar in the inner city compared to surrounding areas. However, the likelihood of POI associated with heroin use, sharing of syringes and sharing of auxiliary injecting equipment were greater in the inner city. In contrast, the likelihood of POI 
associated with local socioeconomic disadvantage was greater in the surrounding areas (Table 3).

Factors associated with HCV incidence

Of 854 participants, 585 (69\%) were HCV seropositive at baseline. One participant was not tested for HCV at follow-up and was excluded (Figure 2). The remaining 268 participants were included in the HCV incidence analyses. The median period of follow-up was 2.77 years (IQR: 1.15-4.87), and the median number of interviews was five (IQR: 3-9). The median interval between HCV tests was 5.55 months (IQR: 3.09-6.57; 2004-March 2011: median: 5.78; IQR: 4.53-7.00; April 2011-2012: median: 3.02, IQR: 2.89-3.61). Overall 92 cases of $\mathrm{HCV}$ were observed over 569.8 person-years corresponding to an incidence rate of 16.15 cases per 100 person-years (95\%CI: 13.16-19.81).

In unadjusted analyses, POI resulted in an approximately threefold increase in the hazard of $\mathrm{HCV}$ infection and residing in the inner-city resulted in an approximately $75 \%$ increase in the hazard of HCV infection (Table 4). An unadjusted analysis of the interaction between POI and place of residence suggested that the effect of POI was higher in the inner city than the surrounding areas (HR: 4.54, 95\%CI: 2.56-8.07 vs. 1.98, 95\%CI: 1.05-3.74, p-value for interaction: 0.058). In addition, unstable housing, incarceration, unstable income, daily or more frequent injection, cocaine injection, crack use, syringe sharing, sharing of auxiliary injection equipment and public injection were all predictors of HCV infection (Table 4). In multivariable models, incarceration, frequency of injection, cocaine injection remained statistically significant after adjusting for covariates (Table 5). The effect of POI varied according to place of residence ( $\mathrm{p}$-value for the interaction term $=0.025$, Table 5 and Figure 3). The adjusted hazard of HCV infection associated with POI among those residing in the inner city was 3.38 (95\% CI: 1.88-6.07-), whereas POI among those residing in the surrounding areas was not associated with a statistically significant increase in the hazard of HCV infection (adjusted HR: 1.26, 95\% CI: 0.65-2.42). Effect sizes did not change when age, gender, syringe sharing, and local socioeconomic disadvantage were added to the model.

Sensitivity analyses

Results were not sensitive to excluding data from Mid-March 2011 onward. 


\section{Discussion}

This study investigated associations between POI and living context in Montréal Island, and the related risk of HCV. POI was more common in inner-city Montréal than in surrounding neighborhoods. This is important because the inner city was characterized by high levels of $\mathrm{HCV}$-related risk factors such as public injecting, unstable housing, unstable income and cocaine injection. Although residing in the inner city was not associated with higher risk of sharing injecting equipment, the odds of POI associated with sharing injecting equipment was higher in the inner-city district. In addition, the hazard of HCV associated with POI was elevated in the inner city compared with the surrounding areas.

While our previous research showed that prescription opioids were a leading risk factor for HCV acquisition in Montréal (21), in this paper, we show that this risk is greatest for innercity Montréal. Prescription opioid injectors had a threefold hazard when living in the inner city, but no elevation in hazard of HCV when living in the surrounding areas. The elevated hazard of $\mathrm{HCV}$ in prescription opioid injectors in the inner city remained after adjusting for other HCV-related risk factors. Moreover, it also remained after adjusting for local socioeconomic disadvantage. This suggests additional unmeasured factors making the inner city a higher risk environment than the surrounding areas.

An ethnographic study of prescription opioid injectors in inner-city Montréal revealed risk patterns that distinguished POI from injection of other drugs, and may shed some light on unmeasured factors contributing to HCV risk (22). In particular, POI leaves a residue on the equipment used to inject which can then be mixed with water and injected later or shared with other users - these are called "washes". The participants interviewed in the ethnographic study describe a culture of giving washes to other PWID as favors. It is hypothesized that this practice is particular to the resource-poor street economy observed in inner-city Montréal, Montréalas a means of solidifying trusting relationships that aid survival on the streets.

Similar gift-giving practices have been observed in the context of black tar heroin injection in San Francisco's street economy (36). It is therefore likely that the practice is less common in the surrounding areas, contributing to the increase in HCV-risk in the inner city associated with POI. Although the participants were aware of harm reduction practices, there appeared 
to be a lack of recognition that using another person's wash posed a similar risk to sharing injecting equipment. Additional mixed methods research is required to elucidate this and other potential unmeasured influences further.

Although we have described the high risk injecting drug scene in inner-city Montréal previously $(1,2)$, our previous reports described factors that mitigated the overall level of risk in the inner city. Our previous studies, which focused on heroin and cocaine injection, demonstrated that within inner-city neighborhoods high risk injecting behaviors such as sharing injecting equipment were more common in areas with high levels of economic disadvantage. However, high risk behaviors were not more common in the inner city overall compared to the surrounding areas (2). This was attributed, at least in part, to the increased availability of sterile needles in the inner city (1). The elevated risk of HCV associated with POI in the inner city observed in this study, is particularly concerning given the high level of harm reduction services already available in the inner-city region. New harm reduction strategies may be required, targeted specifically at people who inject prescription opioids, taking into account the specificity of inner-city PWID communities. The Quebec Institute of Public Health has begun this process by providing safe injection materials designed to reduce injection of 'washes' targeted at POI (37). Increased access to opiate substitution therapy should also be prioritized in the inner city, as it was demonstrated to reduce HCV incidence in several settings. (38-40)

This study has some limitations. Participants were not randomly selected and therefore cannot be considered representative of PWID in Montréal. Compared to participants recruited mainly at needle-syringe programs for a surveillance program in Quebec and Ottawa, this sample has more males and older participants (41). The inner-city Montréal context may not be generalizable to other contexts. However, densely populated inner-urban areas display a core set of common adverse characteristics, including population density, high crime rates, socioeconomic disadvantage, and social inequalities, resulting in vulnerability to injecting drug use (11, 42-44). Our findings may well be relevant to the increased uptake of POI in other inner-urban environments in Canada and elsewhere. Participants in the study moved residence frequently. Most moves were within the inner city or surrounding areas, but a 
substantial number of participants moved between the inner city and surrounding areas (approximately one fifth between the first two interviews). Therefore we modelled the inner city vs surrounding area variable as time-varying. Our follow-up rates were high for a drugusing population and we have previously found that participants retained were similar to those lost except that those retained were more likely to report cocaine and crack use (21); however, our HCV incidence analyses may nonetheless have been influenced by losses to follow-up. Similar to other studies of injecting drug use, data on injection of prescription opioids and other drugs and injecting-related risk factors were based on self-report and may be subject to bias due to perceived social desirability; however, there is some evidence that such self-reports are reliable (45). Data on sharing 'washes' was not collected separately from sharing other injecting equipment, so their hypothesised role as a driver of HCV transmission among prescription opioid users could not be thoroughly tested.

To our knowledge, this is the first study of the influence of living context on POI. We found that POI was more common in inner-city Montréal than in the surrounding areas and that POI in the inner city was associated with a number of injecting-related risk behaviors and elevated risk of $\mathrm{HCV}$ infection. These results are particularly concerning given that our previous research on the influence of living context on heroin and cocaine injection in Montréal showed that while the inner city housed an active "drug scene", the risks seemed to be mitigated by successful needle and syringe programs. This suggests that the increasing prevalence of POI poses novel challenges for harm reduction, and suggests that new interventions are required, tailored to this population.

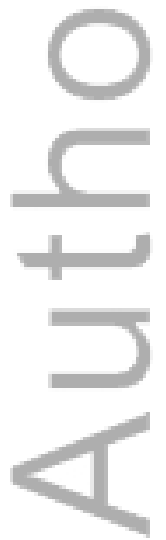




\section{Acknowledgements}

The authors would like to acknowledge Élisabeth Deschênes, Rachel Bouchard and the other staff at the HEPCO Cohort research site. A special thank you is extended to the cohort participants, without whom this research would not be possible.

\section{Funding}

This work was supported by the Canadian Institutes of Health Research (CIHR) [MOP135260; MOP210232] and additional support from the Réseau SIDA et Maladies Infectieuses du Fonds de la Recherche en Santé du Québec [FRSQ5227]. RSD was supported by an NHMRC Early Career Fellowship and MH was supported by an NHMRC Senior Principal Research Fellowship. DJA holds a Clinical Researcher Career Award from the Fonds de la Recherche en Santé du Québec. YK holds a CIHR applied public health Chair in Urban Interventions and Population Health. The Burnet Institute is supported by the Victorian Operational Infrastructure Support program.

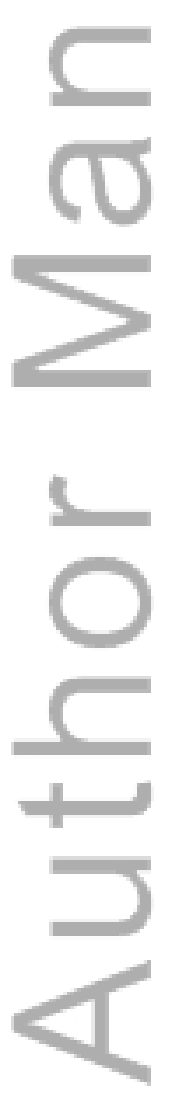




\section{References}

1. Bruneau J., DANiel M., Kestens Y., ZANG G., GÉnÉReuX M. Associations between HIV-related injection behaviour and distance to and patterns of utilisation of syringe-supply programmes, J Epidemiol Community Health 2008: 62: 804-810.

2. GÉNÉREUX M., BRUNEAU J., DANIEL M. Association between neighbourhood socioeconomic characteristics and high-risk injection behaviour amongst injection drug users living in inner and other city areas in Montréal, Canada, International Journal of Drug Policy 2010: 21: 49-

55.

3. FAST D., SHOVELLER J., SHANNON K., KERR T. Safety and danger in downtown Vancouver: Understandings of place among young people entrenched in an urban drug scene, Health \& Place 2010: 16: 51-60.

4. = 'FAST D., SMALL W., WOOD E., KERR T. Coming 'down here': Young people's reflections on becoming entrenched in a local drug scene, Soc Sci Med 2009: 69: 1204-1210.

5. MAas B., Fairbairn N., KerR T., LI K., Montaner J. S. G., Wood E. Neighborhood and HIV infection among IDU: Place of residence independently predicts HIV infection among a cohort of injection drug users, Health \& Place 2007: 13: 432-439.

6. Marshall B., Wood E., Shoveller J., Buxton J., Montaner J., KerR T. Individual, Social, and Environmental Factors Associated with Initiating Methamphetamine Injection: Implications for Drug Use and HIV Prevention Strategies, Prev Sci 2011: 12: 173-180.

7. LLOYD-SMITH E., WOOD E., LI K., MONTANER J. S. G., KERR T. Incidence and determinants of initiation into cocaine injection and correlates of frequent cocaine injectors, Drug Alcohol Depend 2009: 99: 176-182.

8. WYLIE J., SHAH L., JOLLY A. Demographic, risk behaviour and personal network variables associated with prevalent hepatitis $C$, hepatitis $B$, and HIV infection in injection drug users in Winnipeg, Canada, BMC Public Health 2006: 6: 229.

9. WYLIE J. L., SHAH L., JOLLY A. Incorporating geographic settings into a social network analysis of injection drug use and bloodborne pathogen prevalence, Health \& Place 2007: 13: 617-628.

10. LATKIN C. A., WILLIAMS C. T., WANG J., CURRY A. D. Neighborhood social disorder as a determinant of drug injection behaviors: a structural equation modeling approach, Health Psychol 2005: 24: 96-100.

11. SÉGUIN A. M., DIVAY G. Urban poverty: Fostering sustainable and supportive communities, Ottawa: Canadian Policy Research Network Inc.; 2002.

12. WiLLIAMS C. T., METZGER D. S. Race and distance effects on regular syringe exchange program use and injection risks: a geobehavioral analysis, Am J Public Health 2010: 100: 1068-1074.

13. TetraULt J. M., BUtNeR J. L. Non-Medical Prescription Opioid Use and Prescription Opioid Use Disorder: A Review, The Yale Journal of Biology and Medicine 2015: 88: 227-233.

14. UNITED NATIONS OFFICE ON DRUGS AND CRIME. The non-medical use of prescription drugs: policy -direction issues, Vienna: UNODC; 2011.

15. FISCHER B., KEATES A., BÜHRINGER G., REIMER J., REHM J. Non-medical use of prescription opioids and prescription opioid-related harms: why so markedly higher in North America compared to the rest of the world?, Addiction 2014: 109: 177-181.

16. HAVENS J. R., OSER C. B., LEUKEFELD C. G. Injection risk behaviors among rural drug users: Implications for HIV prevention, AIDS Care 2011: 23: 638-645.

17. <Allander Gruber et al 1995.pdf>.

18. Lankenau S. E., KeCojeVIC A., Silva K. Associations between prescription opioid injection and Hepatitis C virus among young injection drug users, Drugs (Abingdon Engl) 2015: 22: 35-42. 
19. Zibbell J. E., Hart-Malloy R., Barry J., Fan L., Flanigan C. Risk Factors for HCV Infection Among Young Adults in Rural New York Who Inject Prescription Opioid Analgesics, Am J Public Health 2014: 104: 2226-2232.

20. LAKE S., KenNedy M. C. Health Outcomes Associated with Illicit Prescription Opioid Injection: A Systematic Review, J Addict Dis 2015: 0.

21. BRUNEAU J., ROY É., ARRUDA N., ZANG G., JUTRAS-AsWAD D. The rising prevalence of prescription opioid injection and its association with hepatitis $C$ incidence among street-drug users, Addiction 2012: 107: 1318-1327.

22. ROYÉ., ARRUDA N., BOURGoIS P. The Growing Popularity of Prescription Opioid Injection in Downtown Montréal: New Challenges for Harm Reduction, Subst Use Misuse 2011: 46: 1142-1150.

23. StATISTICS CANADA. Montréal, Quebec (Code 2466) and Quebec (Code 24) (table). Census Profile 2011 Census, Ottawa; 2012.

24. SAVOIE J., BÉDARD F., COLLINS C. Neighbourhood characteristics and the distribution of crime on the Island of Montréal. Crime and Justice Research Paper series, Ottawa: Statistics Canada; 2006.

25. SeRVICE DE LA MISE en VAleUR dU TERRITOIRE et DU PATRIMOINE. Les arrondissements de Montréal Répertoire socio-démographique et classement par variables, Montréal: Ville de Montréal; 2004.

26. DANIEL M., KESTENS Y. Montréal Epidemiological and Geographic Analysis of Population Health Outcomes and Neighbourhood Effects: MEGAPHONE (Copyright $\left.{ }^{\circledR} 1046898\right)$ ). Montréal: Centre de recherche du Centre hospitalier de I'Université de Montréal (CRCHUM); 2007.

27. VILLE de MontrÉAL. Plan d'action 2005-2007, Montréal: Arrondissement Ville-Marie; 2008.

28. ZEGER S. L., LIANG K.-Y., ALBERT P. S. Models for Longitudinal Data: A Generalized Estimating Equation Approach, Biometrics 1988: 44: 1049-1060.

29. KLeIN J. P., MoesChBeRger M. L. Survival Analysis. Techniques for Censored and Truncated Data New York: Springer-Verlag; 1997.

30. HOSMER D. J., LEMESHOW S. Applied Survival Analysis: Regression Modeling of Time to Event Data New York: John Wiley; 1999.

31. Cornberg M., Razavi H. A., Alberti A., Bernasconi E., Buti M., Cooper C. et al. A systematic review of hepatitis $C$ virus epidemiology in Europe, Canada and Israel, Liver Int 2011: 31: 3060.

32. Pouget E. R., HAgAN H., Des Jarlais D. C. Meta-analysis of hepatitis $C$ seroconversion in relation to shared syringes and drug preparation equipment, Addiction 2012: 107: 10571065.

33. HAGAN H., ThIEDE H., DeS JaRLAIS D. C. Hepatitis C Virus Infection Among Injection Drug Users: Survival Analysis of Time to Seroconversion, Epidemiology 2004: 15: 543-549.

34. ROY É., BOUDREAU J.-F., BoIvIN J.-F. Hepatitis $C$ virus incidence among young street-involved IDUs in relation to injection experience, Drug Alcohol Depend 2009: 102: 158-161.

35. PAtRick D. M., TYNDAll M. W., CoRnelisSe P. G., LI K., Sherlock C. H., ReKART M. L. et al. Incidence of hepatitis $C$ virus infection among injection drug users during an outbreak of HIV infection, CMAJ 2001: 165: 889-895.

36. BOURGOIS P. The moral economies of homeless heroin addicts: Confronting ethnography, HIV risk, and everyday violence in San Francisco shooting encampments, Subst Use Misuse 1998: 33: 2323-2351. 


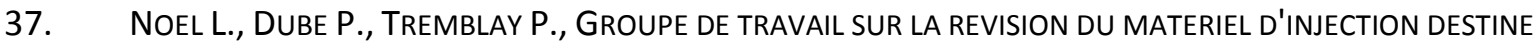
AUX PERSONNES UDI. Material d'injection: reduire les risques chez les injecteurs de medicaments opioides, Quebec: Institut national de sante publique du Quebec; 2015.

38. Turner K. M., Hutchinson S., Vickerman P., Hope V., Craine N., Palmateer N. et al. The impact of needle and syringe provision and opiate substitution therapy on the incidence of hepatitis C virus in injecting drug users: pooling of UK evidence, Addiction 2011: 106: 1978-1988.

39. TSUI J. I., EVANS J. L., LUM P. J., HAHN J. A., PAGE K. Association of opioid agonist therapy with lower incidence of hepatitis $C$ virus infection in young adult injection drug users, JAMA -Intern Med 2014: 174: 1974-1981.

40. Van Den Berg C., Smit C., Van Brussel G., Coutinho R., Prins M., Amsterdam C. Full participation in harm reduction programmes is associated with decreased risk for human

= immunodeficiency virus and hepatitis C virus: evidence from the Amsterdam Cohort Studies among drug users, Addiction 2007: 102: 1454-1462.

41. Royé., Richer I., Morissette C., LeCLeRC P., PARENT R., ClaEsSens C. et al. Temporal changes in risk factors associated with HIV seroconversion among injection drug users in eastern central Canada, AIDS 2011: 25: 1897-1903.

42. Galea S., NANDi A., VLAHOV D. The Social Epidemiology of Substance Use, Epidemiol Rev 2004: 26: 36-52.

43. GaLEA S., VLAHOV D. URBAN HEALTH: Evidence, Challenges, and Directions, Annu Rev Public Health 2005: 26: 341-365.

44. Roberts E. T., Friedman S. R., Brady J. E., Pouget E. R., Tempalski B., Galea S. Environmental conditions, political economy, and rates of injection drug use in large US metropolitan areas 1992-2002, Drug Alcohol Depend 2010: 106: 142-153.

45. GoldSTeIN M. F., Friedman S. R., Neaigus A., JOSE B., ILDEFONSO G., CURTIS R. Self-reports of HIV risk behavior by injecting drug users: are they reliable“, Addiction 1995: 90: 1097-1104.

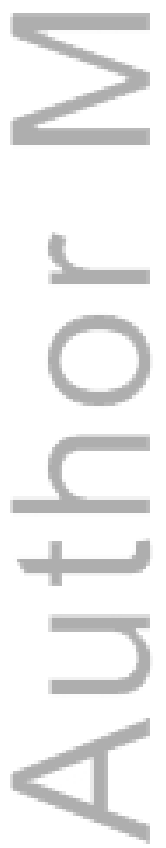

This article is protected by copyright. All rights reserved. 


\section{Tables}

Table 1: Characteristics of the inner city and surrounding area in the Island of Montréal

\begin{tabular}{lll}
\hline & Surrounding area & Inner city \\
\hline Total population & 1802468 & 84013 \\
Average income (\$CAD) & 74410 & 82773 \\
Proportion of households with low income & 22.2 & 33.5 \\
Crime per 1000 inhabitants & 5.32 & 12.01 \\
Crime per square kilometer & 19.85 & 62.69
\end{tabular}

Notes: All data are the most recent available: population data are from 2011, income data are from 2006, and crime data are from 2015.

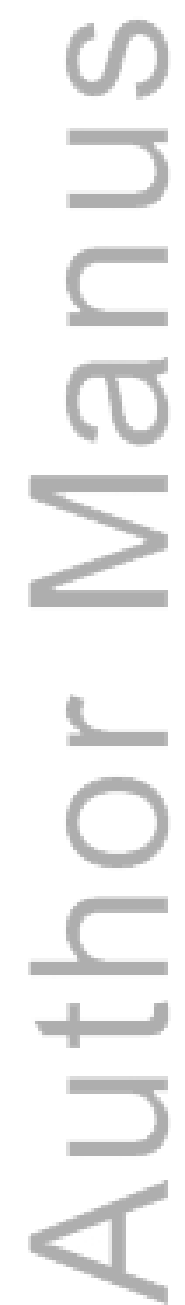

This article is protected by copyright. All rights reserved. 
Table 2: Baseline characteristics of PWID, for residents of the inner-city compared to surrounding areas on Montréal Island

\begin{tabular}{|c|c|c|c|c|}
\hline & $\begin{array}{l}\text { All } \\
\text { n }(\%)\end{array}$ & $\begin{array}{l}\text { Surrounding areas } \\
\text { n }(\%)\end{array}$ & $\begin{array}{l}\text { Inner-city }^{\mathrm{a}} \\
\mathrm{n}(\%)\end{array}$ & p-value \\
\hline $\mathbf{N}$ & 854 & 424 & 430 & \\
\hline \multicolumn{5}{|l|}{ Socio-demographics } \\
\hline Age $<30$ & $215(25)$ & $119(28)$ & $96(22)$ & 0.053 \\
\hline Female $^{\mathbf{b}}$ & $154(18)$ & $96(23)$ & $58(13)$ & $<0.001$ \\
\hline College educated & $152(18)$ & $83(20)$ & $69(16)$ & 0.178 \\
\hline \multicolumn{5}{|l|}{ HCV status } \\
\hline HCV antibody positive & $585(69)$ & $277(65)$ & $308(72)$ & 0.048 \\
\hline \multicolumn{5}{|l|}{ Recent injecting-related behavior } \\
\hline POI $^{\mathbf{c}}$ & $277(32)$ & $107(25)$ & $170(40)$ & $<0.001$ \\
\hline Cocaine injection $^{c}$ & $572(67)$ & $270(64)$ & $302(70)$ & 0.042 \\
\hline Heroin injection ${ }^{c, d}$ & $272(32)$ & $153(36)$ & $119(28)$ & 0.009 \\
\hline Crack use $^{c, e}$ & $434(51)$ & $181(43)$ & $253(59)$ & $<0.001$ \\
\hline Injected at least daily ${ }^{\mathrm{c}}$ & $135(16)$ & $62(15)$ & $73(17)$ & 0.346 \\
\hline Public injecting ${ }^{\mathrm{f}}$ & $455(53)$ & $189(45)$ & $266(62)$ & $<0.001$ \\
\hline Syringe sharing ${ }^{d, f}$ & $252(30)$ & $114(27)$ & $138(32)$ & 0.100 \\
\hline Auxillary equipment sharing ${ }^{d, f}$ & $335(39)$ & $155(37)$ & $189(44)$ & 0.106 \\
\hline \multicolumn{5}{|l|}{ Recent housing and income } \\
\hline Any unstable income $\mathrm{g}^{\mathrm{g}, \mathrm{i}}$ & $479(56)$ & $222(53)$ & $257(60)$ & 0.032 \\
\hline Unstable housing ${ }^{\mathrm{d}, \mathrm{h}, \mathrm{i}}$ & $378(44)$ & $87(21)$ & $291(68)$ & $<0.001$ \\
\hline \multicolumn{5}{|l|}{ History of incarceration } \\
\hline Incarceration ever $^{\mathbf{j}}$ & $685(80)$ & $328(78)$ & $357(83)$ & 0.037 \\
\hline Recent incarceration ${ }^{i, j}$ & $123(14)$ & $56(13)$ & $67(16)$ & 0.337 \\
\hline \multicolumn{5}{|l|}{ Local socioeconomic disadvantage } \\
\hline High & $464(54)$ & $132(31)$ & $332(77)$ & $<0.001$ \\
\hline
\end{tabular}

Notes: a. Inner-city is defined as the Ville-Marie neighbourhood. Surrounding areas are other areas within Montréal Island. Place of residence was defined as the place where they had most often slept during the past month. b. Two participants identified as transgender and were not included in the denominator for percentage of females. c. Past month. d. Data were missing for one participant. e. Data were missing for eight participants. f.

This article is protected by copyright. All rights reserved. 
Past six months (2004-Mid-March 2011) or past three months (Mid-March 2011-2012). g. Stable income includes employment (including full-time and part-time) and government benefits. Unstable income includes support from friends and family, sex work and related employment (e.g., pimping), illegal activities (e.g, robbery, fraud, drug trade), selling personal items, artistic activities in the metro or on the streets, and begging, among other things. Data on source of income were missing for three participants. h. Unstable housing was defined as living on the street, in shelters or in apartment-hotels rented on a monthly basis (indicating a rapid turnover compared to typical 12-month rent-lease accommodation standard in Montréal). i. Past three months. j. Data were missing for two participants. k. High local socioeconomic disadvantage: $>=40 \%$ of households below the low income cut-off within 250 meters of the participants' postal code.

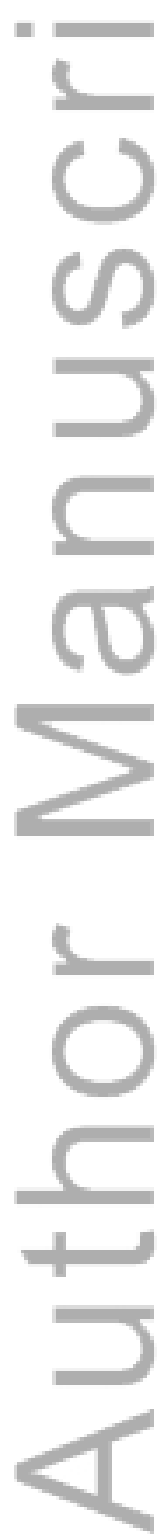


Table 3: Correlates of prescription opioid injection overall and by residence in the inner-city compared to surrounding areas.

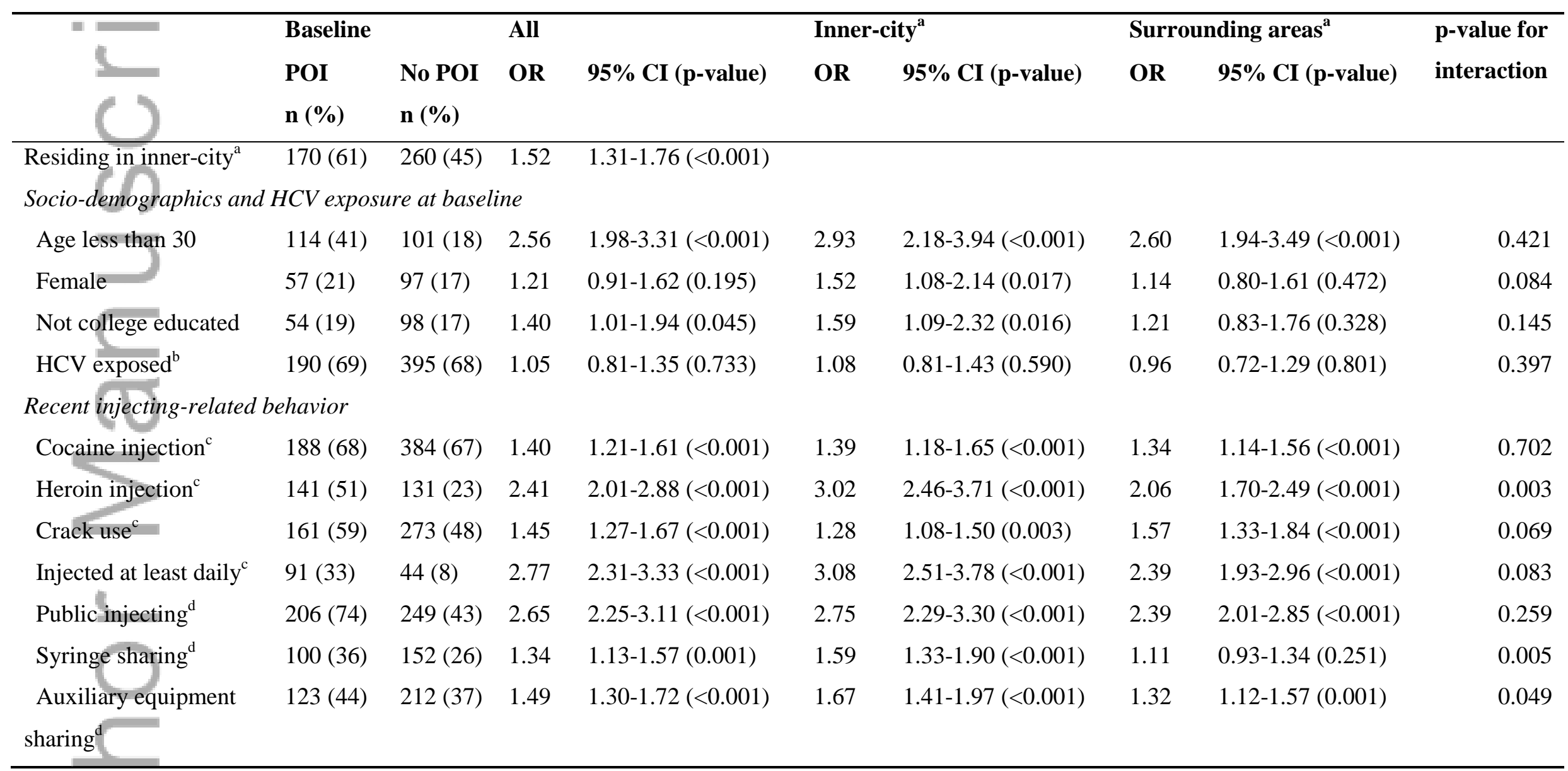




\begin{tabular}{|c|c|c|c|c|c|c|c|c|c|}
\hline Any unstable income $e^{e, f}$ & $188(68)$ & $291(51)$ & 1.58 & $1.40-1.78(<0.001)$ & 1.65 & $1.40-1.94(<0.001)$ & 1.49 & $1.28-1.73(<0.001)$ & 0.351 \\
\hline Unstable housing ${ }^{\mathrm{f}, \mathrm{g}}$ & $147(53)$ & $231(40)$ & 1.66 & $1.44-1.91(<0.001)$ & 1.64 & $1.36-1.97(<0.001)$ & 1.37 & $1.12-1.67(0.002)$ & 0.184 \\
\hline Incarceration $^{\mathrm{f}}$ & $48(17)$ & $75(13)$ & 1.18 & $1.00-1.39(0.053)$ & 1.13 & $0.90-1.42(0.274)$ & 1.17 & $0.92-1.51(0.206)$ & 0.839 \\
\hline High local SE & $166(60)$ & $298(52)$ & 1.25 & $1.11-1.40(<0.001)$ & 0.91 & $0.77-1.08(0.302)$ & 1.37 & $1.16-1.64(<0.001)$ & 0.001 \\
\hline
\end{tabular}

Notes: OR: Odds ratio, CI: confidence interval; a. Inner-city is defined as the Ville-Marie neighbourhood. Surrounding areas are other areas within Montréal Island. Place of residence was defined as the place where they had most often slept during the past month. b. Defined by anti-HCV status. c. Past month. d. Past six months (2004-Mid-March 2011) or past three months (Mid-March 2011-2012). e. Stable income includes employment (including full-time and part-time) and government benefits. Unstable income includes support from friends and family, sex work and related employment (e.g., pimping), illegal activities (e.g, robbery, fraud, drug trade), selling personal items, artistic activities in the metro or on the streets, and begging, among other things. f. Past three months. g. Unstable housing was defined as living on the street, in shelters or in apartment-hotels rented on a monthly basis (indicating a rapid turnover compared to typical 12-month rent-lease accommodation standard in Montréal). d. SE: socioeconomic, High local SE disadvantage: >=40\% of households below the low income cut-off within 250 meters of the participants' postal code.

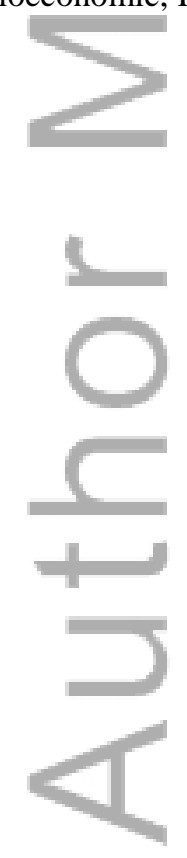

This article is protected by copyright. All rights reserved. 
Table 4: Unadjusted estimated relative hazard of hepatitis C virus (HCV) seroconversion according to socio-demographic and behavioural factors for 268 initially HCV-negative cohort participants in Montréal Island, 2004-2012.

\begin{tabular}{|c|c|c|c|c|c|c|}
\hline . & & $\mathbf{P Y}$ & Cases & $\begin{array}{l}\text { Incidence rate } \\
(95 \% \mathrm{CI})^{\mathrm{a}}\end{array}$ & HR $(95 \%$ CI $)$ & $\begin{array}{l}\mathbf{p -} \\
\text { value }\end{array}$ \\
\hline Residing in inner- & Yes & 219.60 & 50 & $22.77(17.26-30.04)$ & $1.73(1.15-2.62)$ & 0.009 \\
\hline city $^{\mathrm{b}}$ & No & 350.18 & 42 & $11.99(8.86-16.23)$ & 1 & \\
\hline \multicolumn{7}{|c|}{ Socio-demographics } \\
\hline \multirow[t]{2}{*}{ Age } & $<30$ & 207.54 & 42 & $20.24(14.96-27.38)$ & $1.40(0.93-2.11)$ & 0.110 \\
\hline & $>=30$ & 362.24 & 50 & $13.80(10.46-18.21)$ & 1 & \\
\hline \multirow[t]{2}{*}{ Gender } & Female & 102.34 & 15 & $14.66(8.84-24.31)$ & $0.84(0.48-1.46)$ & 0.540 \\
\hline & Male & 464.41 & 77 & $16.58(13.26-20.73)$ & 1 & \\
\hline \multirow{2}{*}{ College educated } & No & 477.87 & 80 & $16.74(13.45-20.84)$ & $1.32(0.72-2.41)$ & 0.376 \\
\hline & Yes & 91.91 & 12 & $13.06(7.42-22.99)$ & 1 & \\
\hline \multicolumn{7}{|c|}{ Recent injecting-related behavior } \\
\hline \multirow[t]{2}{*}{$\mathrm{POI}^{\mathrm{c}, \mathrm{d}}$} & Yes & 116.71 & 46 & $39.41(29.52-52.62)$ & $3.21(2.13-4.86)$ & $<0.001$ \\
\hline & No & 453.06 & 46 & $10.15(7.60-13.56)$ & 1 & \\
\hline \multirow{4}{*}{$\begin{array}{l}\text { Cocaine } \\
\text { injection }^{\mathrm{c}} \\
\text { Heroin injection }^{\mathrm{c}}\end{array}$} & Yes & 266.29 & 76 & $28.54(22.79-35.73)$ & $4.36(2.53-7.51)$ & $<0.001$ \\
\hline & No & 303.48 & 16 & $5.27(3.23-8.61)$ & 1 & \\
\hline & Yes & 180.55 & 38 & $21.05(15.31-28.93)$ & $1.38(0.91-2.09)$ & 0.134 \\
\hline & No & 389.23 & 54 & $13.87(10.63-18.11)$ & 1 & \\
\hline \multirow[t]{2}{*}{ Crack use $\mathrm{e}^{\mathrm{c}}$} & Yes & 247.39 & 56 & $22.64(17.42-29.41)$ & $1.80(1.18-2.75)$ & 0.006 \\
\hline & No & 318.70 & 36 & $11.30(8.15-15.66)$ & 1 & \\
\hline \multirow{2}{*}{$\begin{array}{l}\text { Injected at least } \\
\text { daily }^{\mathrm{c}}\end{array}$} & Yes & 61.91 & 29 & $46.84(32.55-67.41)$ & $3.64(2.33-5.67)$ & $<0.001$ \\
\hline & No & 507.87 & 63 & $12.40(9.69-15.88)$ & 1 & \\
\hline \multirow{2}{*}{ Public injecting $\mathrm{g}^{\mathrm{e}}$} & Yes & 211.71 & 63 & $29.76(23.25-38.09)$ & $2.92(1.87-4.56)$ & $<0.001$ \\
\hline & No & 358.07 & 29 & $8.10(5.63-11.65)$ & 1 & \\
\hline \multirow{2}{*}{ Syringe sharing ${ }^{\mathrm{e}}$} & Yes & 101.89 & 32 & $31.41(22.21-44.41)$ & $1.92(1.24-2.96)$ & 0.003 \\
\hline & No & 467.89 & 60 & $12.82(9.96-16.52)$ & 1 & \\
\hline Auxiliary & Yes & 154.19 & 45 & $29.18(21.79-39.09)$ & $1.99(1.32-3.02)$ & 0.001 \\
\hline $\begin{array}{l}\text { equipment } \\
\text { sharing }^{\mathrm{e}}\end{array}$ & No & 409.29 & 47 & $11.48(8.63-15.28)$ & 1 & \\
\hline
\end{tabular}

This article is protected by copyright. All rights reserved. 


\begin{tabular}{lllllll}
\hline \multicolumn{6}{l}{ Recent housing, income, incarceration, and local neighborhood socioeconomic disadvantage } \\
Any unstable & Yes & 305.97 & 65 & $21.24(16.66-27.09)$ & $1.97(1.26-3.09)$ & 0.003 \\
income $^{\mathrm{f}}$ & No & 262.94 & 27 & $10.27(7.04-14.97)$ & 1 & \\
Housing $^{\mathrm{f}}$ & Unstable & 181.25 & 50 & $27.59(20.91-36.40)$ & $2.12(1.40-3.21)$ & $<0.001$ \\
& Stable & 387.27 & 42 & $10.85(8.01-14.67)$ & 1 & \\
\multirow{2}{*}{ Incarceration $^{\mathrm{f}}$} & Yes & 51.33 & 19 & $37.02(23.61-58.04)$ & $2.38(1.43-3.95)$ & 0.001 \\
& No & 518.08 & 73 & $14.09(11.20-17.72)$ & 1 & \\
Local SE & High & 264.54 & 56 & $21.17(16.29-27.51)$ & $1.68(1.11-2.56)$ & 0.015 \\
disadvantage & Low & 305.24 & 36 & $11.79(8.51-16.35)$ & 1 & \\
\hline
\end{tabular}

Notes: PY: person-years; CI: confidence interval; HR: hazard ratio. a. Incidence rate per 100 person-years. b. Inner-city is defined as the Ville-Marie neighborhood. Surrounding areas are other areas within Montréal Island. Place of residence was defined as the place where they had most often slept during the past month. c. Past month; d. POI: Prescription opioid injection. e. Past six months (2004-Mid-March 2011) or past three months (Mid-March 2011-2012). f. Past three months. g. SE: socioeconomic, High local SE disadvantage: $>=40 \%$ of households below the low income cut-off within 250 meters of the participants' postal code.

This article is protected by copyright. All rights reserved. 
Table 5: Adjusted estimated relative hazard of hepatitis C virus (HCV) seroconversion according to socio-demographic and behavioural factors for 268 initially HCV-negative cohort participants in Montréal Island, 2004-2012.

\begin{tabular}{|c|c|c|c|c|c|}
\hline & & Model 1 $^{\mathrm{h}}$ & & Model 2 $^{\text {h }}$ & \\
\hline & & $\operatorname{AHR}(95 \% \mathrm{CI})$ & p-value & $\operatorname{AHR}(95 \%$ CI) & p-value \\
\hline Age & $<30$ & $1.08(0.68-1.72)$ & 0.739 & & \\
\hline & $>=30$ & 1.00 & & & \\
\hline Gender & Female & $1.22(0.67-2.23)$ & 0.515 & & \\
\hline - & Male & 1.00 & & & \\
\hline Recent cocaine & Yes & $3.48(1.98-6.10)$ & $<0.001$ & $3.53(2.03-6.14)$ & $<0.001$ \\
\hline injection $^{a}$ & No & 1.00 & & & \\
\hline Recently & Yes & $2.40(1.47-3.91)$ & $<0.001$ & $2.47(1.55-3.93)$ & 0.000 \\
\hline $\begin{array}{l}\text { injected at least } \\
\text { daily }^{\mathrm{a}}\end{array}$ & No & 1.00 & & & \\
\hline Recent syringe & Yes & $1.13(0.70-1.81)$ & 0.620 & & \\
\hline sharing $^{b}$ & No & 1.00 & & & \\
\hline Recent & Yes & $2.01(1.17-3.45)$ & 0.012 & $1.98(1.18-3.32)$ & 0.010 \\
\hline incarceration $^{c}$ & No & 1.00 & & & \\
\hline Local SE & High & $1.46(0.93-2.31)$ & 0.102 & & \\
\hline disadvantage $^{\mathrm{d}}$ & Low & 1.00 & & & \\
\hline POI by area of & Surrounding areas ${ }^{\mathrm{f}}$ & $1.21(0.62-2.35)$ & 0.582 & $1.26(0.65-2.42)$ & 0.496 \\
\hline residence $^{\mathrm{a}, \mathrm{e}}$ & Inner city ${ }^{\mathrm{g}}$ & $3.20(1.76-5.80)$ & $<0.001$ & $3.38(1.88-6.07)$ & $<0.001$ \\
\hline
\end{tabular}

Notes: AHR: adjusted hazard ratio; CI: confidence interval. a. Past month. b. Past six months (2004-Mid-March 2011) or past three months (Mid-March 2011-2012). c. Past three months. d. SE: socioeconomic, High local SE disadvantage: $>=40 \%$ of households below the low income cut-off within 250 meters of the participants' postal code. e. POI: prescription opioid injection; Inner-city is defined as the Ville-Marie neighborhood. Surrounding areas are other areas within Montréal Island. Place of residence was defined as the place where they had most often slept during the past month. $p$-value for the interaction term: model $1 p=0.029$, model $2 p=0.025$; no evidence of violation of the assumption of proportional hazards: model $1 \mathrm{p}=0.9182$, model $2 \mathrm{p}=0.8751$. $\mathrm{f}$. AHR of hepatitis $\mathrm{C}$ infection among $\mathrm{POI}$ in the surrounding areas using non-POI in the surrounding area as a referent category. g. AHR for hepatitis $\mathrm{C}$ infection among POI in the inner-city using non-POI in the inner-city as a referent category. h. a likelihood ratio test comparing the two models showed no evidence that model 1 was a better fit than model 2 ( $\mathrm{p}=0.4474)$. 


\section{Figures}

Figure 1: Map of the Island of Montréal, with the inner-city region highlighted.
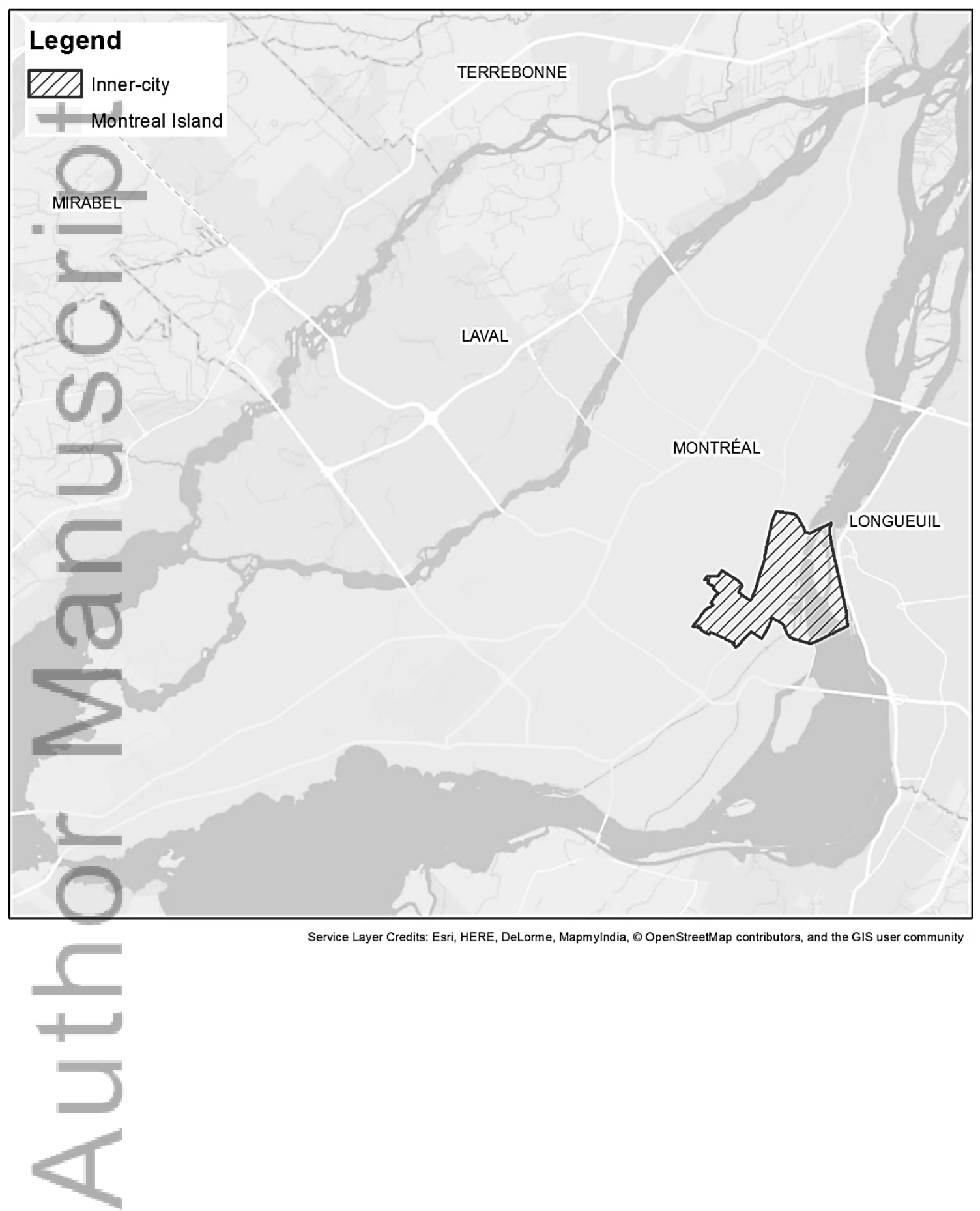

Service Layer Credits: Esri, HERE, DeLorme, MapmyIndia, ๑ OpenStreetMap contributors, and the GIS user community

This article is protected by copyright. All rights reserved. 
Figure 2: Flow-chart describing recruitment, follow-up and inclusion criteria

Notes: *Participants who moved from Montréal Island were allowed to continue to participate in the study if they were willing to travel to Montréal Island for interviews or could cease participation. Participants who were incarcerated were sometimes able to be interviewed in prison depending on the nature and location of the detention facility.

\section{8 participants \\ = recruited before}

September 242012 and

eligible for follow-up

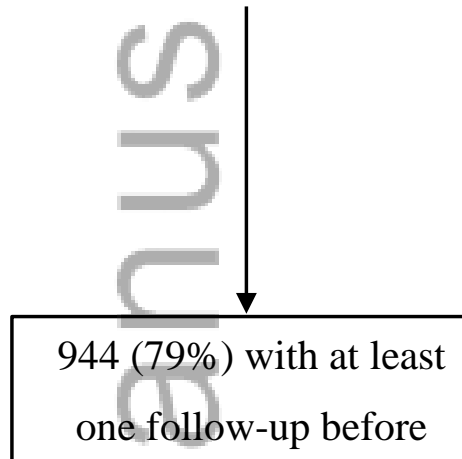

December 242012

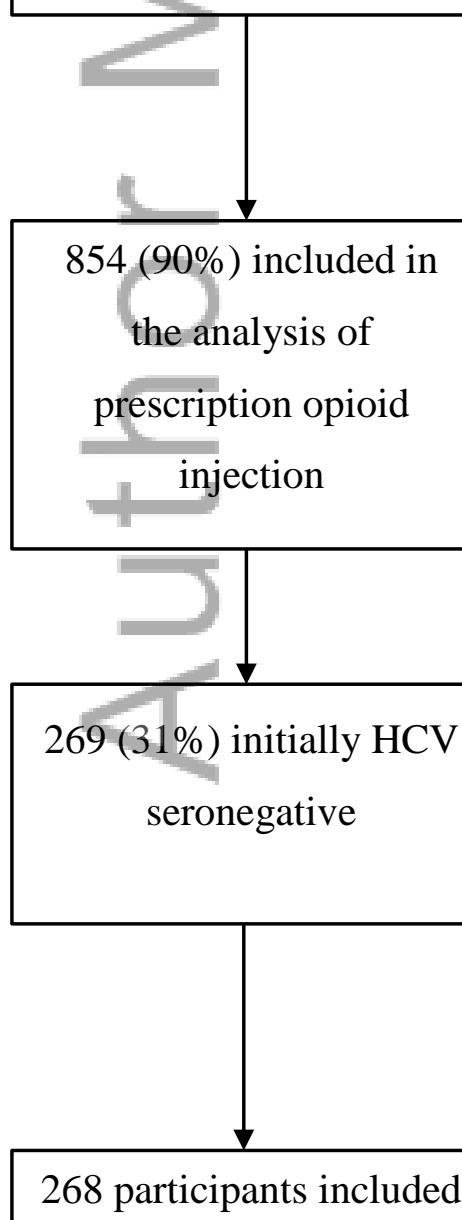

in the HCV incidence

analysthis article is protected by copyright. All rights reserved. 
Figure 3: Kaplan Meier estimates of HCV seroconversion proportion by place of residence and POI

Notes: $\mathrm{IC}=$ inner-city, $\mathrm{SA}=$ surrounding areas, $\mathrm{POI}=$ prescription opioid injection. Log-rank test p-value: $<0.001$.

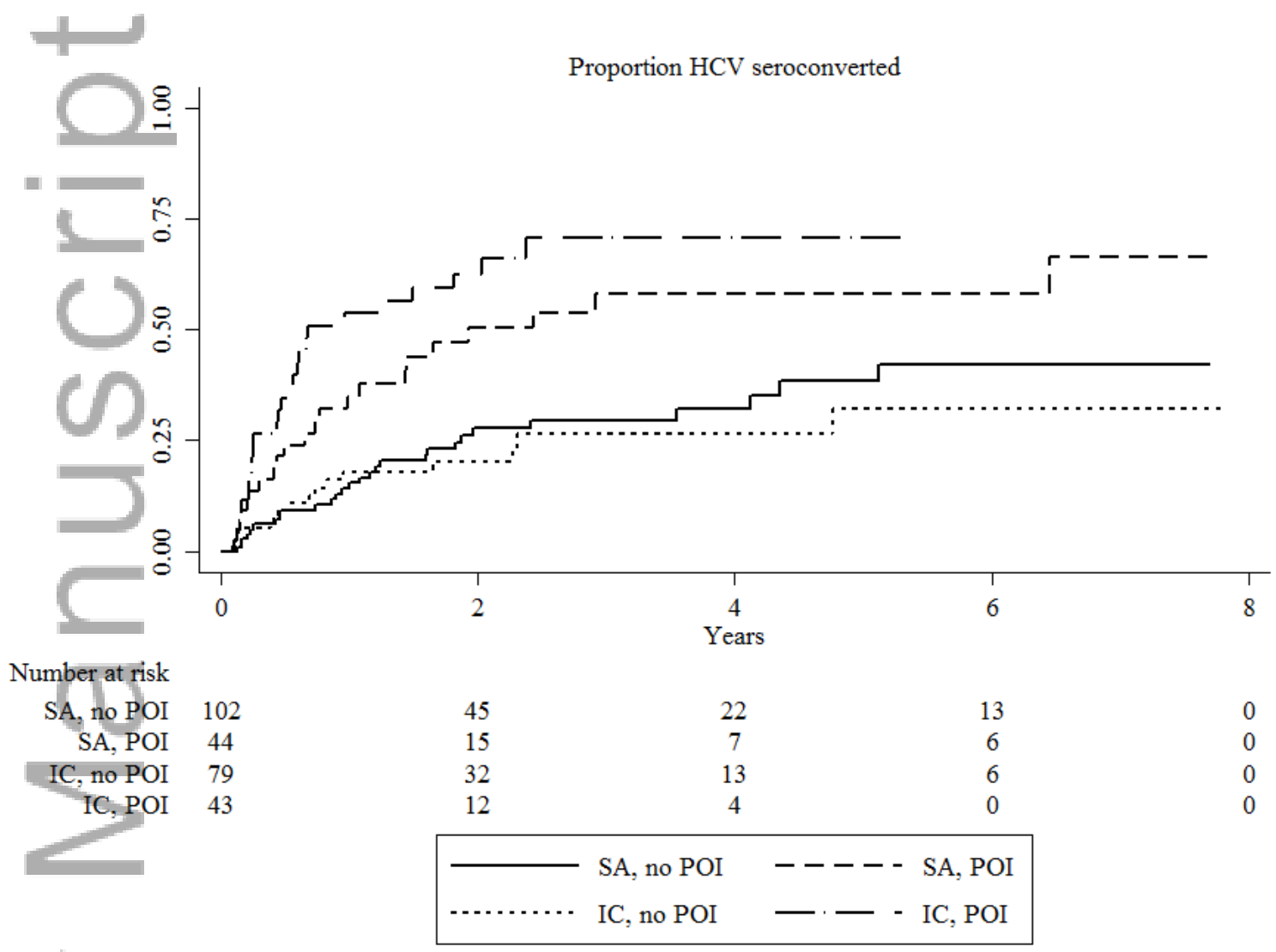

This article is protected by copyright. All rights reserved. 


\section{University Library}

\section{- M M N E R VA A gateway to Melbourne's research publications}

Minerva Access is the Institutional Repository of The University of Melbourne

Author/s:

Sacks-Davis, R;Daniel, M;Roy, E;Kestens, Y;Zang, G;Ramos, Y;Hellard, M;Aswad,

DJ;Bruneau, J

Title:

The role of living context in prescription opioid injection and the associated risk of hepatitis C infection

Date:

2016-11-01

Citation:

Sacks-Davis, R., Daniel, M., Roy, E., Kestens, Y., Zang, G., Ramos, Y., Hellard, M., Aswad, D. J. \& Bruneau, J. (2016). The role of living context in prescription opioid injection and the associated risk of hepatitis C infection. ADDICTION, 111 (11), pp.1985-1996. https:// doi.org/10.1111/add.13470.

Persistent Link:

http://hdl.handle.net/11343/291524 